Review

\title{
Continuous Flow Synthesis of Zeolite-A from Coal Fly Ash Utilizing Microwave Irradiation with Recycled Liquid Stream
}

\author{
Salman Bukhari and Sohrab Rohani \\ Department of Chemical and Biochemical Engineering, Western University, Canada
}

\section{Article history}

Received: 16-12-2016

Revised: 06-06-2017

Accepted: 16-06-2017

Corresponding Author:

Salman Bukhari

Department of Chemical and

Biochemical Engineering,

Western University, Canada

Tell: +1 (519) 661-2116

Email: srohani@uwo.ca

\begin{abstract}
Coal Fly Ash (CFA) was converted to zeolite using continuous microwave reactors while minimizing the wastewater produced during the zeolitization process. At bench scale, a continuous flow tubular microwave reactor was used to explore the effect of microwave irradiation on the crystallinity of the product. The waste water was reused in consecutive runs and Inductively Coupled Plasma (ICP) analysis was conducted during and after each run to observe the concentration of the cations. An increase in the production of hydroxysodalite compared to zeolite-A was noted at higher levels of microwave energy. The XRD and SEM analyses were also conducted to corroborate the results. The Cation Exchange Capacity (CEC) measurement showed the highest value of $0.405 \mathrm{meq} / \mathrm{g}$ when Deionized (DI) water was used, the CEC dropped to $0.177 \mathrm{meq} / \mathrm{g}$ for thrice recycled waste stream. It was also found that higher microwave irradiation resulted in faster crystal growth and the product crystallinity reached its maximum at $810 \mathrm{~W}$ of microwave irradiation in $60 \mathrm{~min}$ while $335 \mathrm{~W}$ of microwave irradiation resulted in the same crystallinity after $120 \mathrm{~min}$ of reaction.
\end{abstract}

Keywords: Coal Fly Ash, Synthesis, Microwave, Continuous Flow, Bench Scale, Zeolite A, Hydroxysodalite

\section{Introduction}

Despite public and private investments and advances in renewable energies, coal remains the leading source of electricity generation in the world. Currently about $40 \%$ of the global electricity is produced by coal and it is predicted to account for $33 \%$ by 2035 according to International Energy Agency (IEA, 2013) Even with this reduced share, coal will stay a major source of electricity production around the world. In 2010 alone, coal fired power plants produced about 780 million ton coal combustion products such as Coal Fly Ash (CFA) worldwide. Only about $50 \%$ of these products were recycled (Heidrich et al., 2013). There has been much research conducted on producing value added products such as zeolites (Bukhari et al., 2015a) from the accumulated CFA. Pioneering studies in zeolitization of CFA was reported using conventional heating (Holler and Wirsching, 1985; Shigemoto et al., 1993; Hollman et al., 1999), however, recently many researchers have focused their efforts on utilizing novel energy sources such as Microwave (MW) (Behin et al., 2014; Bukhari et al., 2014; Querol et al., 1997) and ultrasound (Bukhari et al., 2016; Belviso et al., 2011; Wang and Zhu, 2005; Musyoka et al., 2011a).

Zeolites are crystalline aluminosilicates with a framework structure containing pores occupied by water and metallic cation. Zeolite structure is based on silicate chemistry with tetrahedron structure similar to aliphatic carbon chemistry. Silicate $\left(\mathrm{SiO}_{4}\right)$ unit within a structure is linked to other silicate through shared oxygen atoms. Zeolite frameworks exclusively contain $\mathrm{Al}^{+3}$ and $\mathrm{Si}^{+4}$, therefore producing a negative charge in the frameworks. These frameworks contain cations to electrochemically balance the negative charge introduced by $\mathrm{Al}$ atoms present in aluminosilicates. Cations neutralize the excess anionic charge; and can undergo reversible ion exchange. Zeolite frameworks are also rigid which enables them to remain unaltered when water is adsorbed or desorbed.

The $\mathrm{Si}$ to $\mathrm{Al}$ ratio can range from 1 to $\infty$, where the latter is complete siliceous compound, $\mathrm{SiO}_{2}$. The lower limit of $\mathrm{Si}$ to $\mathrm{Al}$ ratio of 1 is observed where $\left[\mathrm{AlO}_{4}\right]^{-1}$ tetrahedra are not placed adjacent to each other because the negative charge on them repel each other (Breck, 1975). Some zeolites also show adsorption of anions and 
organics from aqueous solution. Modification of zeolites can be achieved by several methods such as acid treatment, ion exchange and surfactant functionalization, endowing the modified zeolites higher adsorption capacity for organics and anions (Wang and Peng, 2010).

Silicate and aluminate tetrahedra are the primary building units of zeolites, whereas, the secondary building units refer to the characteristic arrangements of tetrahedra giving rise to frameworks in the zeolite's structure. The framework structures are listed in the publications of Atlas of Zeolite Framework Types which in its sixth edition lists 176 unique zeolite framework structures each assigned a 3-letter code by the commission of International Zeolite Association (Baerlocher et al., 2007).

Zeolites are well known for their ability to act as catalysts, ion exchangers, adsorbents and membrane. Due to these abilities they find many potential applications in the fields of pollution control (Moreno et al., 2001), radioactive waste management (Malekpour et al., 2008; Sinha et al., 1995), petrochemical reactions (Landau et al., 2003; Babajide et al., 2012), water purification (Savage and Diallo, 2005; Theron et al., 2010; Shoumkova, 2011; Fan et al., 2008), purification of gasses (Srinivasan and Grutzeck, 1999; Cheung and Hedin, 2014; Wdowin et al., 2014) and agriculture (Khan et al., 2013).

Most of the studies conducted in the field of zeolitization of CFA have utilized deionized, distilled or industrial water, however, there have been a few reports which studied other sources of water. Belviso et al. (2009) synthesized zeolite-X from CFA and seawater by pre-treatment fusion with

$\mathrm{NaOH}$ followed by hydrothermal crystallization. The synthesis yield at different crystallization temperature was higher using seawater. Hussar et al. (2017) synthesized zeolite-A by hydrothermal process using sodium silicate, sodium aluminate and the by-product of an aluminum etching process. Chemical composition of the aluminum etching by-product consisted mainly of oxides $\mathrm{Al}_{2} \mathrm{O}_{3}(92 \%), \mathrm{Na}_{2} \mathrm{O}(6 \%)$ and $\mathrm{SiO}_{2}(0.5 \%)$. Their results indicated that higher synthesis reaction temperature and reaction time resulted in the synthesis of zeolite-A with a higher crystallinity. The effect of using industrial waste brine solution instead of ultrapure water, was investigated by Musyoka et al. (2011b). They used coal fly ash as silicon feedstock and high halide brine obtained from the retentate effluent of a reverse osmosis mine water treatment plant, as the solvent. The brine contained a high sodium and potassium levels and low concentrations of toxic elements. In addition, there was a trace of aluminum equal to $48.38 \mu \mathrm{g} \mathrm{L}^{-1}$. The use of brine as a solvent resulted in the formation of hydroxysodalite zeolite. Musyoka et al. (2013) used two types of mine waters (i.e., acid and circumneutral) obtained from coal mining operation instead of pure water to manufacture zeolites$\mathrm{X}$ and zeolite-P by means of a two-step indirect (fusion followed by hydrothermal crystallization) and a direct method, respectively. The important cationic species of circumneutral water were: (Na: $952 \mathrm{mg} \mathrm{L}^{-1}, \mathrm{Mg}$ : $38 \mathrm{mg}$ $\mathrm{L}^{-1}$ and $\mathrm{Ca}: 19 \mathrm{mg} \mathrm{L}^{-1}$ and $\mathrm{Si}: 1.2 \mathrm{mg} \mathrm{L}^{-1}$ without any $\mathrm{Al}$ ) and acid drainage water contained: (Fe: $4694 \mathrm{mg}$ $\mathrm{L}^{-1}$, Na: $68 \mathrm{mg} \mathrm{L}{ }^{-1}, \mathrm{Mg}: 386 \mathrm{mg} \mathrm{L}^{-1}, \mathrm{Ca}: 458 \mathrm{mg} \mathrm{L}^{-1}$, $\mathrm{Al}: 613 \mathrm{mg} \mathrm{L}^{-1}$ and $\mathrm{Si}: 31 \mathrm{mg} \mathrm{L}^{-1}$ ). The use of circumneutral mine water resulted in similar quality zeolite-P and zeolite- $X$, whereas the use of acidic mine drainage led to the formation of hydroxysodalite. Behin et al. (2014) utilized liquid waste stream from a Plasma Electrolytic Oxidation (PEO) process. The electrolytes used in PEO typically contained low concentrations of alkaline solutions (Dehnavi et al., 2013). The waste stream of PEO contained $\mathrm{Na}(673 \mathrm{mg}$ $\left.\mathrm{L}^{-1}\right), \mathrm{K}\left(497 \mathrm{mg} \mathrm{L}^{-1}\right)$, Si (295 $\left.\mathrm{mg} \mathrm{L}^{-1}\right)$ and $\mathrm{Al}(10 \mathrm{mg}$ $\mathrm{L}^{-1}$ ) cations and the zeolite synthesized with this waste stream had a lower CEC and water carrying capacity compared to zeolite synthesized with DI water.

In addition to using waste water as mentioned above, Behin et al. (2016) reused and recycled the waste stream from zeolitization process. It was found that zeolite-P can be produced utilizing waste water stream.

The present work explores the utilizing of recycled waste water for the production of zeolite-A at larger scale unlike previous works focusing on the MW zeolitization of CFA at lab scale (Behin et al., 2014; Bukhari et al., 2014; Belviso et al., 2009; Musyoka et al., 2013; Behin et al., 2016).

There has been some research done on a larger scale utilizing conventional heating. Moriyama et al. (2005) used a $0.6 \mathrm{~L}$ reactor for the conversion of CFA to zeolite-P at an elevated pressure of $0.48 \mathrm{MPa}$ and $153^{\circ} \mathrm{C}$. The liquid to solid ratio was $1.1 \mathrm{~L} \mathrm{~kg}^{-1}$ in $\mathrm{NaOH}$ solution (3 M). The zeolite-P produced, had a CEC ranging from 1.25 to $2.0 \mathrm{meq} / \mathrm{g}$. Querol et al. (2001) produced zeolite$\mathrm{P}$ in a $10,000 \mathrm{~L}$ reactor. The reaction was conducted at $149.5^{\circ} \mathrm{C}$ and $0.35 \mathrm{MPa}$. The liquid to solid ratio in the slurry was $1.68 \mathrm{~L} \mathrm{~kg}^{-1}$ in $2.4 \mathrm{M} \mathrm{NaOH}$ solution.

We report the work conducted in a bench MW reactor with a volume of $0.2 \mathrm{~L}$.

\section{Materials and Methods}

\section{Materials}

Coal fly ash was obtained from a coal fired power plant (OPG, Nanticoke, ON, Canada) and was stored in a sealed container before use. Sodium hydroxide (Alphachem, Canada) and sodium aluminate anhydrous (Sigma-Aldrich, USA) were of analytical grade and used as received. Deionized (DI) water was used for the preparation of the solutions. Other chemicals used for characterization tests were of analytical grade. 


\section{Methods}

Two sets of experiments were conducted; the first set of experiments were conducted to study the effect of MW power while the second set of experiments were to evaluate the effect of recycling the effluent stream. The schematics of the Milestone FlowSynth MW (Milestone, Italy) bench scale reactor with $1 \mathrm{~L}$ of reaction slurry capacity is shown in Fig. 1. There is an inner recycled stream from the FlowSynth MW reactor/crystallizer to a mixing/feed tank which is equipped with a condenser and a heating jacket for proper temperature control. The purpose of the inner recycle stream is to increase the exposure time of the slurry to the MW irradiation. The residence time of the slurry in the FlowSynth crystallizer/reactor per pass at a slurry flow rate is given in Table 1, while the overall run time was for $250 \mathrm{~min}$.

\section{MW Power Experiments}

The first set of experiments, without the overall recycle stream from the MW crystallizer/reactor to the digestion tank, was carried out by adding $109 \mathrm{~g}$ of sodium hydroxide granules with $91 \mathrm{~g}$ of fly ash $(\mathrm{NaOH} / \mathrm{CFA}$ ratio of 1.2$)$ to $850 \mathrm{~mL}$ deionized water and mixed/digested at $60^{\circ} \mathrm{C}$ for $16 \mathrm{~h}$. Subsequently, $150 \mathrm{~mL}$ aqueous sodium aluminate solution (concentration: $0.155 \mathrm{~g} \mathrm{~mL}^{-1}$ ) was also added in the ageing tank. The slurry with extra sodium aluminate was aged for two hours at room temperature and mixed in the mixing/feed tank attached to the MW reactor as shown in Fig. 1.

The system was kept at atmospheric pressure at $95^{\circ} \mathrm{C}$ with the use of a reflux condenser. The slurry was circulated through the MW reactor and samples were withdrawn from the mixing tank at predetermined times. The slurry flow was adjusted to increase the total or cumulative MW irradiation to the reaction slurry to study the effect of MW irradiation on the zeolitization process. The experimental runs with different slurry flow rates, residence times and corresponding MW power are outlined in Table 1. The block diagram of the runs without the overall recycle stream to the digestion tank is shown in Fig. 2.

Table 1. The MW power experiment sample numbers with corresponding MW power, slurry flow rates and the residence times

\begin{tabular}{llll}
\multicolumn{2}{c}{ per pass } & & \\
\hline Sample & Average MW power $(\mathrm{W})$ & 130 & Residence time $(\mathrm{s})$ \\
\hline P-300 & 335 & 150 & 1.54 \\
P-400 & 395 & 200 & 1.33 \\
P-600 & 600 & 250 & 1.00 \\
P-800 & 810 & & 0.80 \\
\hline
\end{tabular}

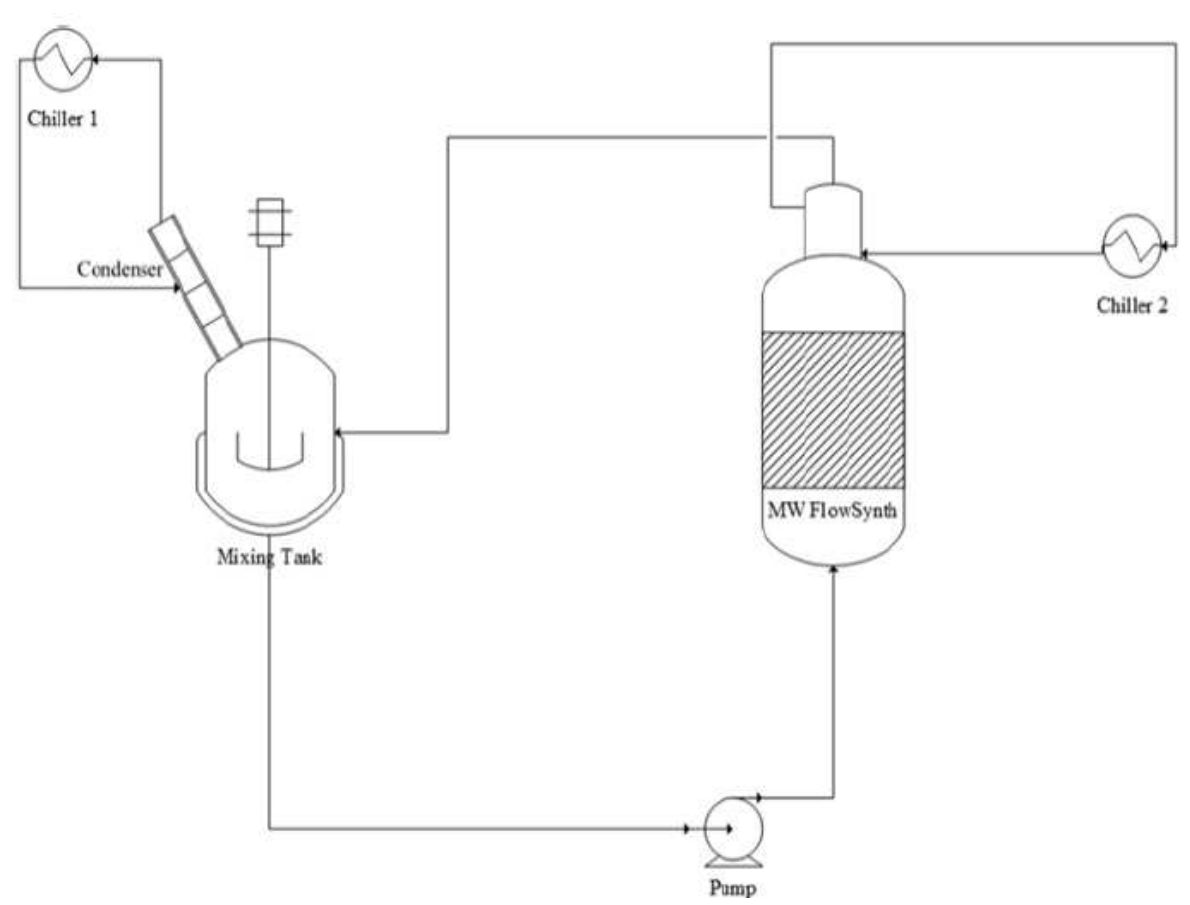

Fig. 1. The schematics of the bench scale FlowSynth MW crystallizer/reactor with an inner recycle stream to increase the exposure time to the MW irradiation 


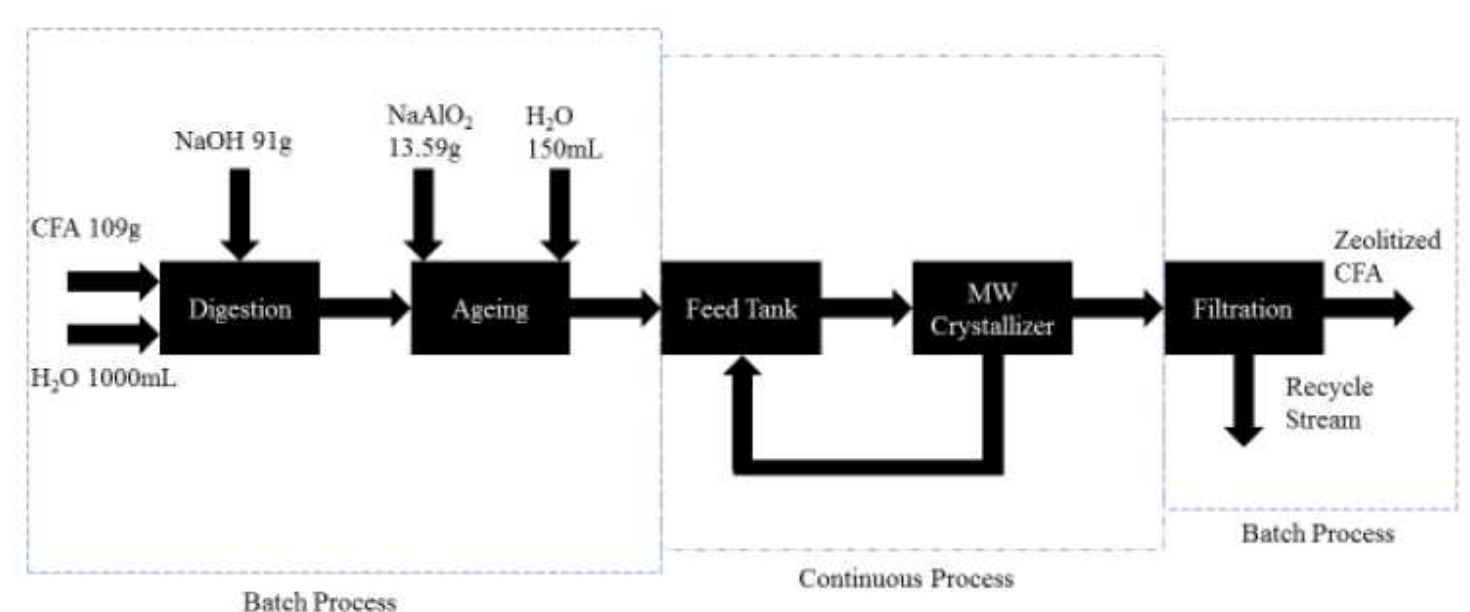

Fig. 2. The block diagram of runs without the overall recycle stream from the MW reactor/crystallizer to the digestion tank

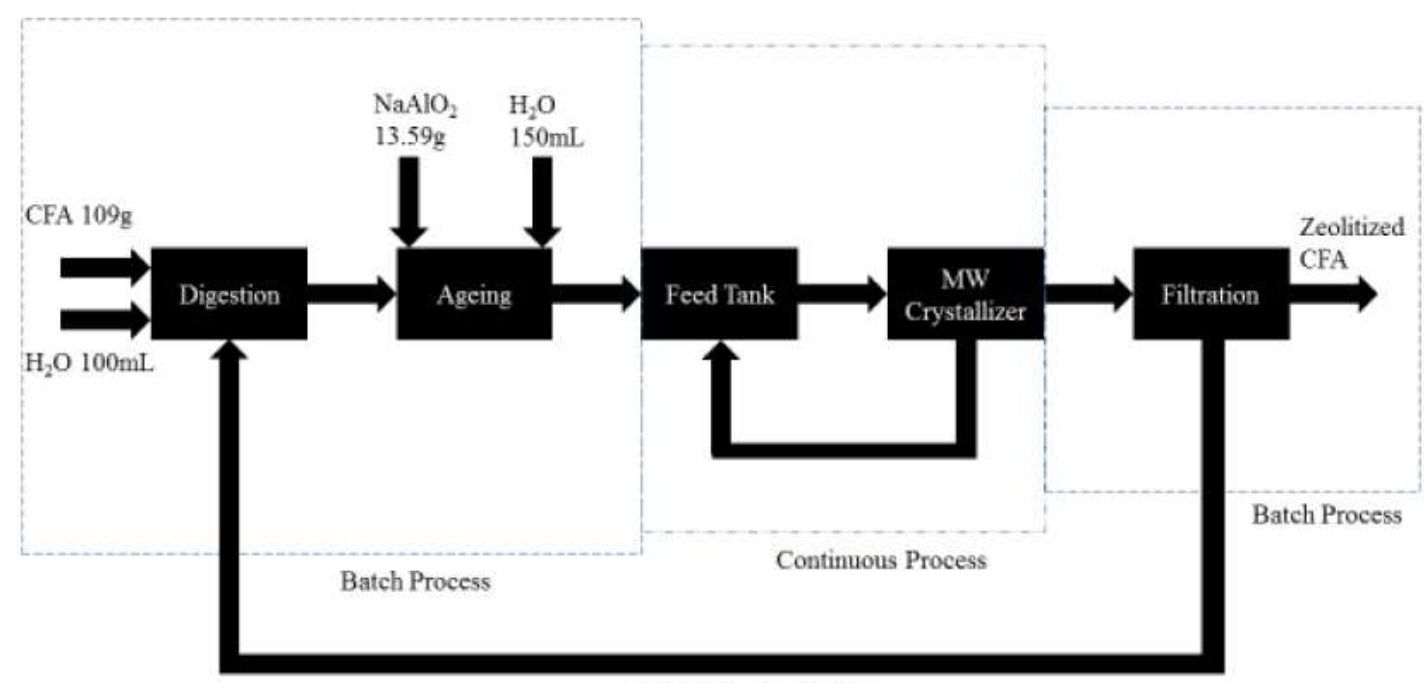

Recycle Stream $750 \mathrm{~mL}$

Fig. 3. The block diagram of runs with the overall recycle stream from the MW reactor/crystallizer to the digestion tank

\section{Experiments with the Overall Recycled Stream}

The slurry for the first run was prepared with DI water according to the procedure discussed above. For the successive runs with an overall recycled stream, the slurry withdrawn from the FlowSynth MW crystallizer/reactor after removing the product zeolitized CFA in the filtration system, was mixed of the DI water. Seven hundred fifty $\mathrm{mL}$ of the effluent stream from the FlowSynth MW reactor/crystallizer was recovered and mixed with the DI water to replenish the solvent. The loss of $250 \mathrm{~mL}$ of solvent in each run was associated with two major factors, some of the liquid remained in the zeolitized CFA, in addition, the liquid content inside the reactor could not be completely removed. The block diagram of the runs with the overall recycled stream is illustrated in Fig. 3.
Samples were withdrawn after each digestion and MW treatment (crystallization) to observe the metal ion concentration in the solution throughout the experiments.

\section{Characterization}

Inductively Coupled Plasma Atomic Emission Spectroscopy (ICP-AES) was used to measure the concentration of different ions in the solution both after the digestion and MW reaction. Concentrations were found using a Perkin-Elmer Optima-3300 DV ICPAtomic Emission Spectrometer (USA). Chemical composition of the CFA sample was determined by means of X-Ray Fluorescence spectroscopy (XRF) utilizing PANalytical PW2400 Wavelength Dispersive. Rigaku-Miniflex powder diffractometer (Japan) was 
used to collect XRD data of the synthesized zeolites using $\mathrm{CuK} \alpha$ ( $\lambda$ for $\mathrm{K} \alpha=1.54059 \AA$ ) over the range of $5^{\circ}<2 \theta<25^{\circ}$ with a step width of $0.02^{\circ}$. The characteristic peaks of zeolitized CFA were at the $2 \theta$ of $7.20^{\circ}, 10.19^{\circ}, 12.49^{\circ}, 16.14^{\circ}$ and $24^{\circ}$ (Treacy and Higgins, 2007). The peak areas were calculated using MDI-Jade v 7.5 software. The crystal size distribution and morphology of the zeolites were studied by Scanning Electron Microscope (SEM); Hitachi S 2600N SEM (Tokyo, Japan) operating at $5 \mathrm{kV}$ of acceleration voltage. The Cationic Exchange Capacity (CEC) was measured using ammonium acetate saturation method (over a 5 day period) based on Bain and Smith (1987). The zeolite samples were soaked in a $1 \mathrm{~N}$ solution of ammonium acetate for 5 days in the same end-over-end shaker. After 5 days, the zeolite samples were filtered and allowed to air dry. The dried samples were then washed using $100 \mathrm{~mL}(5 \times 20 \mathrm{~mL})$ of an aqueous solution of $10 \mathrm{wt} \% \mathrm{NaCl}$ and $1 \mathrm{vol} \%$ $\mathrm{HCl}$ to remove the fixated ammonium. The ammonium concentration in the supernatant was then measured. The ammonium concentration was correlated to peak absorbance intensity between 550 and $800 \mathrm{~nm}$ using UV-VIS spectroscopy. To prepare the samples for the UV-VIS spectroscopy, sodium salicylate, sodium hydroxide and sodium hypochlorite were added and 5 minutes allowed to elapse for the reaction to proceed to completion.

\section{Results and Discussion}

\section{X-Ray Analysis (XRD and XRD)}

The main sources of $\mathrm{Si}$ and $\mathrm{Al}$ from CFA for hydrothermal zeolitization process are summarized in Table 2. The XRD data indicated that the main components of the CFA were amorphous aluminosilicate as well as quartz and mullite that existed as crystalline structures.

\section{The MW Power Experiments}

\section{X-Ray Diffraction Analysis (XRD)}

After the digestion in the mixing tank, the feed pump was turned on at a predetermined speed indicated in Table 1 to continuously supply the CFA slurry through the MW reactor. It took the system about $10 \mathrm{~min}$ to reach steady state. Following steady state, samples were collected every $30 \mathrm{~min}$ to conduct XRD analysis. A series of characteristic peaks were observed at the $2 \theta$ of $7.25^{\circ}, 10.25^{\circ}, 12.55^{\circ}, 16.20^{\circ}, 21.80^{\circ}, 24.10^{\circ}, 27.25^{\circ}$, $30.10^{\circ}$ and $34.35^{\circ}$, which were in agreement with reference peaks that belong to zeolite-A. The calculated characteristic peaks areas of the samples collected are indicated in Fig. 4.
The XRD analysis indicate that irrespective of MW power all the samples require at least $30 \mathrm{~min}$ before zeolitic crystals can be registered by XRD. Therefore, it indicates that the nucleation of zeolitic crystals is not a strong function of the MW power. However, once crystal growth starts, the samples irradiated under higher MW power grow faster compared to the samples irradiated with lower power. This can be concluded by observing the stronger growth of characteristic peak area of samples P800 and P-600 which were irradiated with higher MW energy compared to samples P-400 and P-300 which were irradiated with lower MW energy. However, once the area of the characteristic peak of a sample reached a maximum, it did not increase with the increases MW power input. All samples eventually had the similar crystallinity irrespective of the MW power input level. The positive correlation between the crystal growth and microwave irradiation in zeolite-A crystallization is in agreement with earlier work (Bukhari et al., 2005b).

\section{Scanning Electron Microscope (SEM)}

The SEM images of the solids were taken over the $4 \mathrm{~h}$ of MW irradiation. The SEM images are illustrated in Fig. 5a-e.

The SEM analysis of the MW irradiated samples show that the surface of the CFA is the nucleation and crystal growth site for the zeolites. As the reaction progresses, small cubic zeolitic-A crystals can be deciphered in the SEM images. These structures grow larger with increase in the time of MW irradiation. The SEM results corroborate with the XRD analysis which shows an increase of characteristic peak area as the MW irradiation time is increased, indicating the production of zeolite-A over the reaction period.

Table 2. XRF analysis of chemical composition of CFA

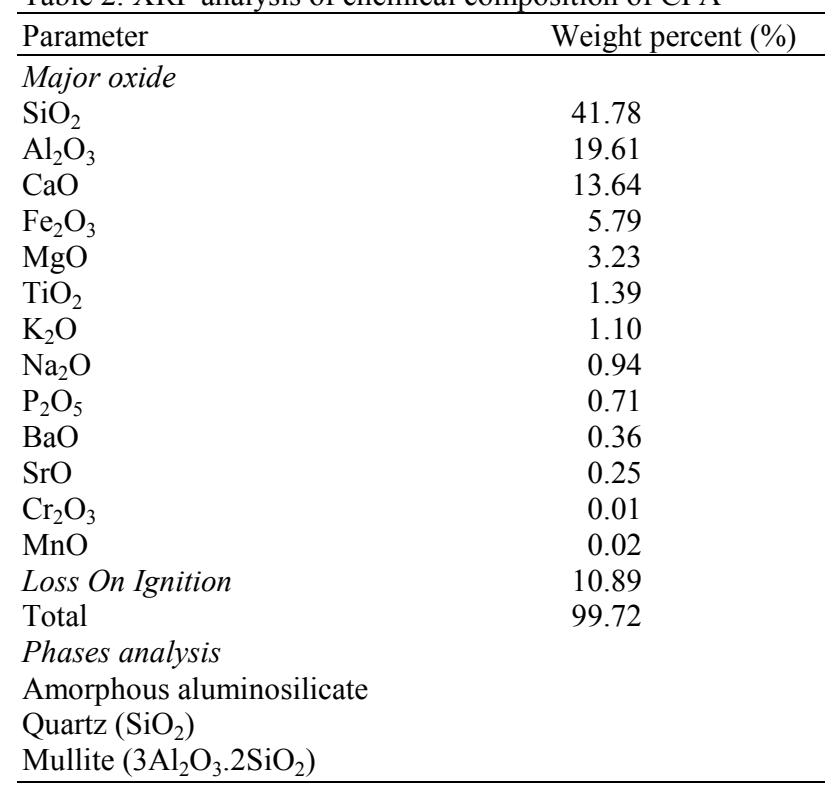




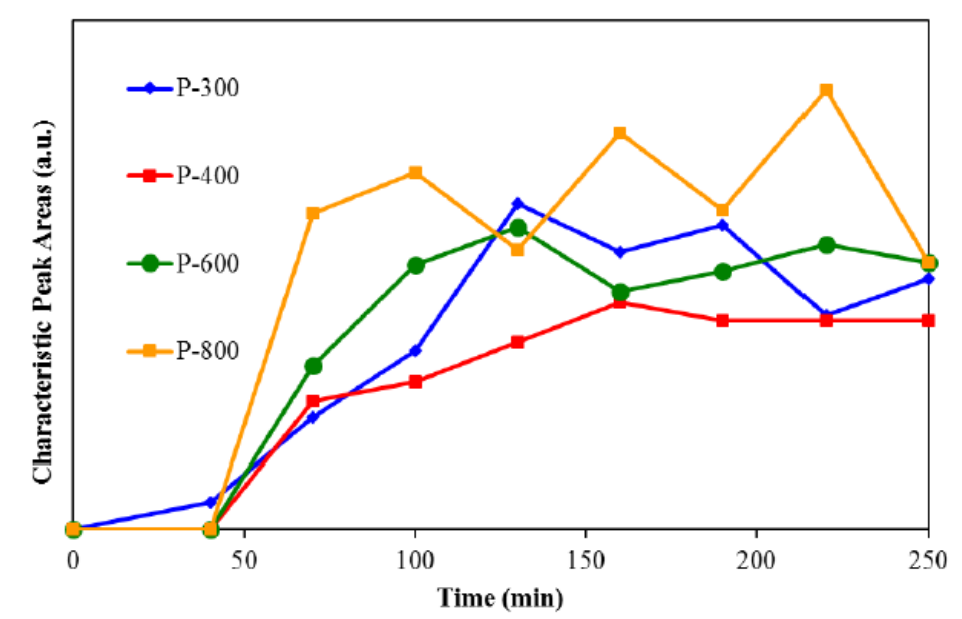

Fig. 4. XRD characteristic peak areas with respect to time

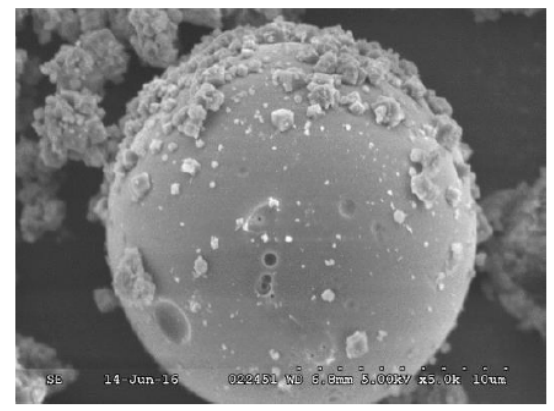

(a)

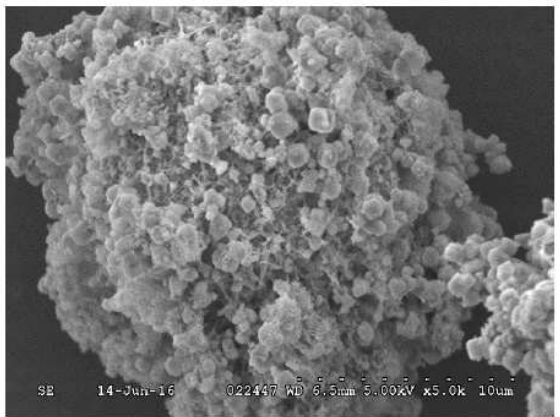

(c)

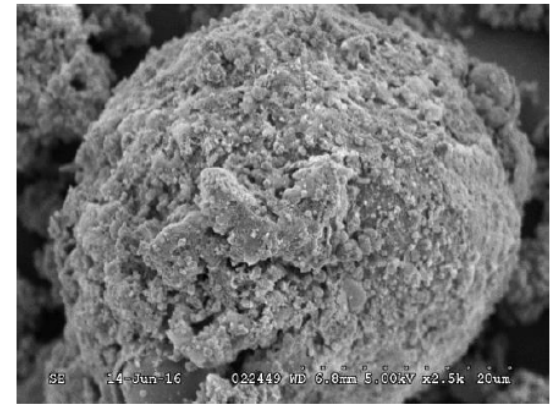

(b)

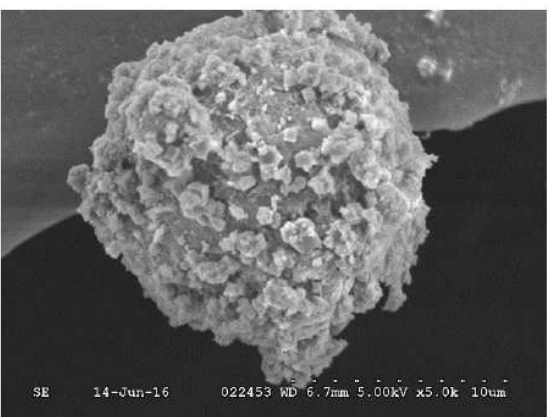

(d)

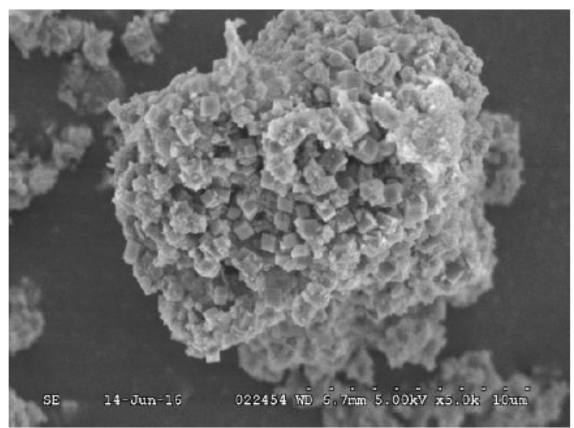

(e)

Fig. 5. SEM images of zeolitized CFA at (a) $30 \mathrm{~min}$ (b) $60 \mathrm{~min}$ (c) $90 \mathrm{~min}$ (d) $120 \mathrm{~min}$ (e) $150 \mathrm{~min}$ 


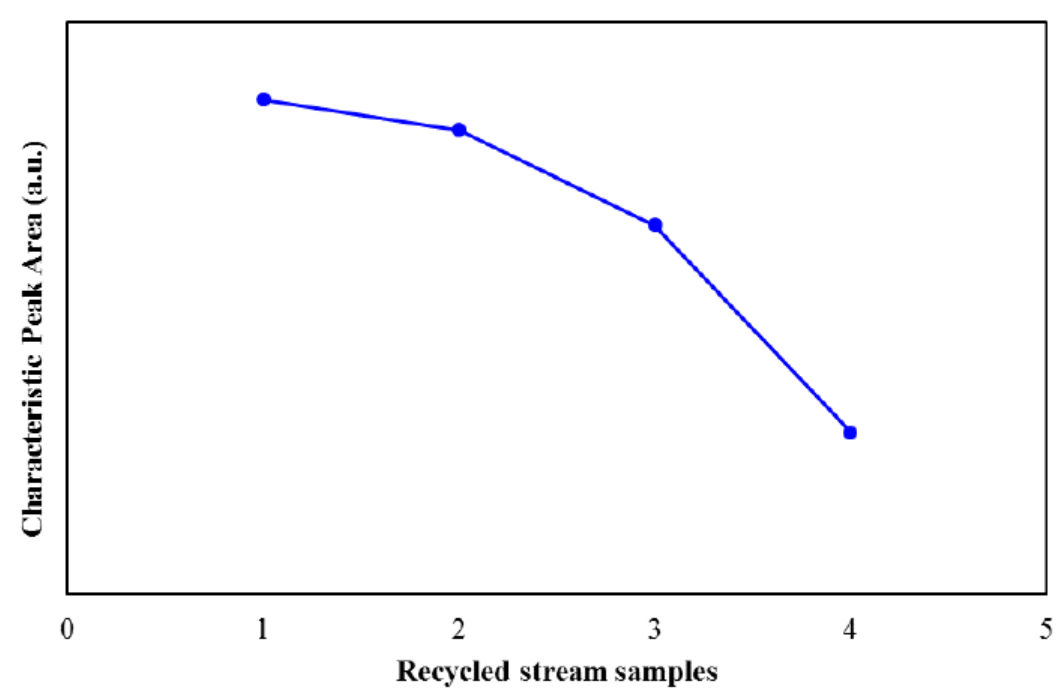

Fig. 6. The XRD characteristic peak area results for recycled stream

\section{Recycled Stream Experiments}

\section{X-Ray Diffraction Analysis (XRD)}

The XRD analyses for the recycled stream experiments were conducted after the end of each run. The characteristic peak areas are illustrated in Fig. 6.

It was observed that after each run the crystallinity of the final product was reduced, indicating that the recycling reduces the quality of zeolitic crystals compared to using fresh water. Previous works have also reported lower crystallinity (Musyoka et al., 2013; Behin et al., 2016) utilizing different waste streams during the zeolitization of CFA. As the recycle stream is re-used the crystallinity of the product is further decreased. This can be explained due to the increased concentration of metallic ions with consecutive runs. This observation is later corroborated with the ICP results.

\section{Inductively Coupled Plasma Atomic Emission Spectroscopy (ICP-AES)}

The ICP analysis was conducted for recycle stream experiments to track the concentration of metallic ions in the solution over the length of the whole experiment. Samples for the ICP analysis were drawn after digestion (designated by D in Fig. 7 and crystallization (designated by $\mathrm{C}$ in the figure).

Metallic ions including $\mathrm{Al}, \mathrm{As}, \mathrm{Fe}, \mathrm{K}, \mathrm{Si}$ and $\mathrm{V}$ were detected in the solvent. The concentration of both light and heavy metals increased with each run as indicated in Fig. 7a-c. The solid bars represent the ICP result after digestion and the shaded bars represent ICP results after digestion.

Figure $7 \mathrm{a}$ indicates that after digestion in the first run $\left(D_{0}\right)$ both the aluminum and silicon concentration can be detected which indicates the dissolution of aluminosilicate contents of CFA in the solvent. Aluminum content is seen to increase in each ICP sample after crystallization $\left(C_{0}\right.$ to $C_{3}$ ) due to the addition of additional aluminum source before crystallization step. Extra aluminum is necessary for the crystallization of zeolite-A as it is observed that without extra aluminum zeolite-P is obtained (Behin et al., 2016; Aldahri et al., 2016).

Each ICP after crystallization shows lower concentration of $\mathrm{Si}$ compared to the corresponding digestion step, indicating that the Si constituents in the solution crystallize as part of zeolitic framework. It can be further noted that each consecutive digestive step results in lower concentration of Si compared to the last digestion step signifying that recycle stream is no longer able to dissolve the CFA contents compared to the fresh water. This effect becomes more significant as the liquid stream is further recycled. This could be due to the saturation of the reactant solvent with metallic ions and reducing the ionic diffusion from the CFA matrix to the solution in the digestion step.

Figure $7 \mathrm{~b}$ and $7 \mathrm{c}$ show the concentration of As, Cr, K and $\mathrm{V}$ over the recycled stream run. It can be observed that the concentration of these metallic ions constantly increases as the recycled stream is reused.

\section{Scanning Electron Microscope (SEM)}

The SEM images of the recycled stream experiments shown in Fig. 8 were obtained for samples at the end of each 4 hour run. The images showed cubic zeolite-A and rough spherical hydroxysodalite structure. The amount of zeolitic crystals present, depended on the reactant solvent and the number of times the reactant solvent stream was recycled. The first two samples, one crystallized in DI water and the other in once recycled stream, had significantly higher cubic structures. However, successive experiments had fewer cubic zeolite-A structures and significantly more rough spherical hydroxysodalite 
structures. The presence of various alkali metal cations in otherwise identical gels, results in the synthesis of different zeolites (Khodabandeh, 1997). The interaction between negatively charged silicate, aluminate and aluminosilicate species and the cation species is extremely important in the crystallization of the zeolite. The presence of heavy metal cations in the solution and their interaction with the aluminosilicate can be hypothesized as one reason for the production of hydroxysodalite in the recycled stream.

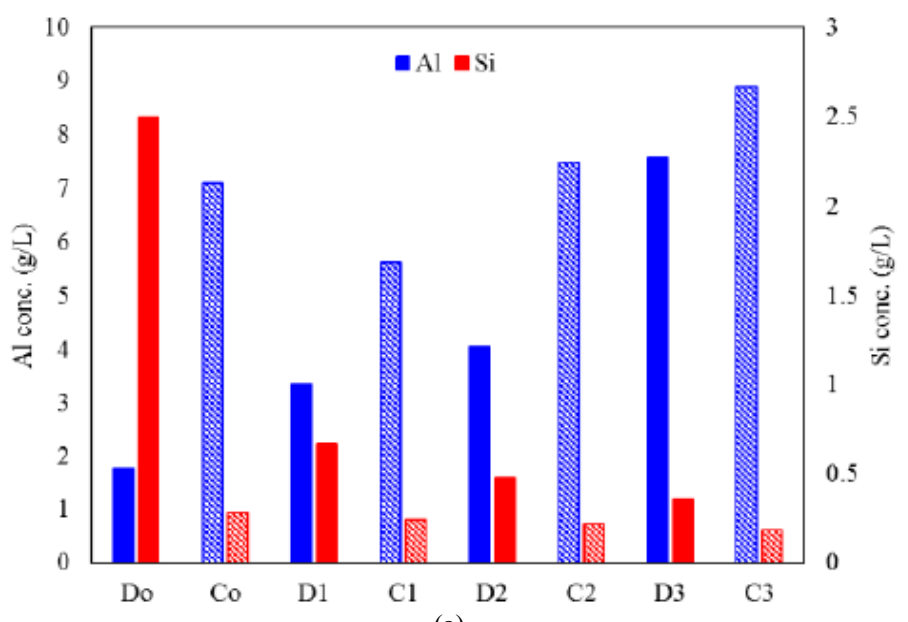

(a)

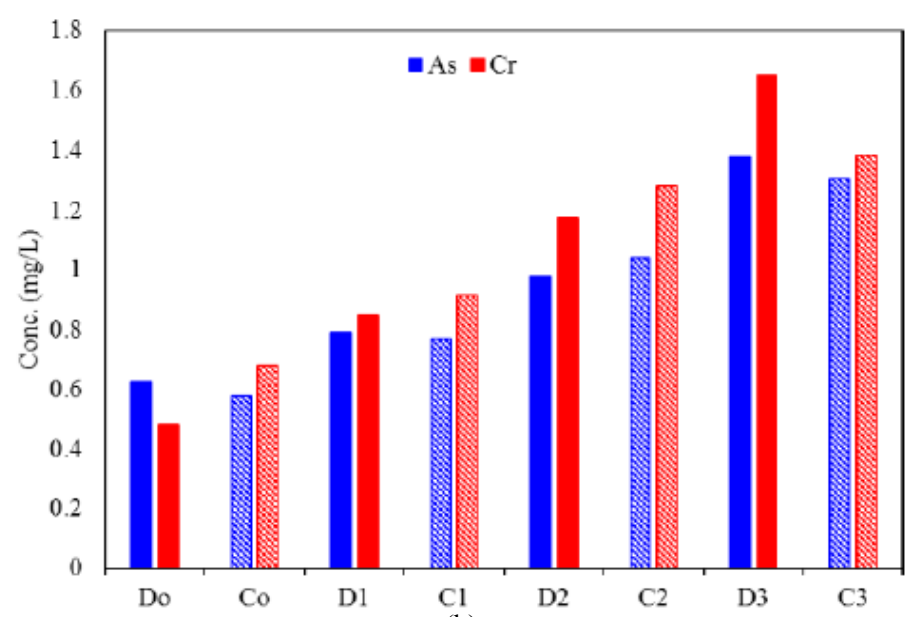

(b)

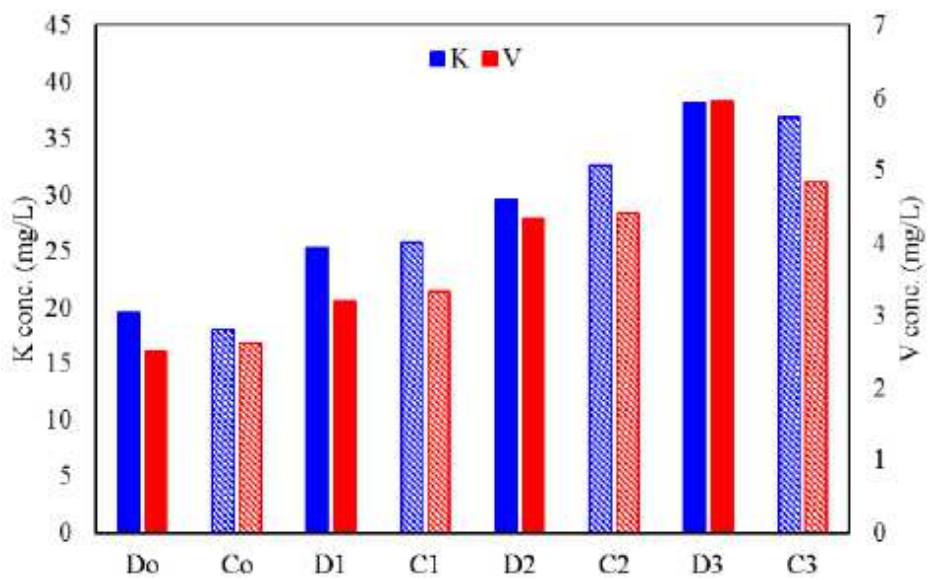

(c)

Fig. 7. ICP analysis of (a) Al, Si; (b) As, Cr and (c) K, V 


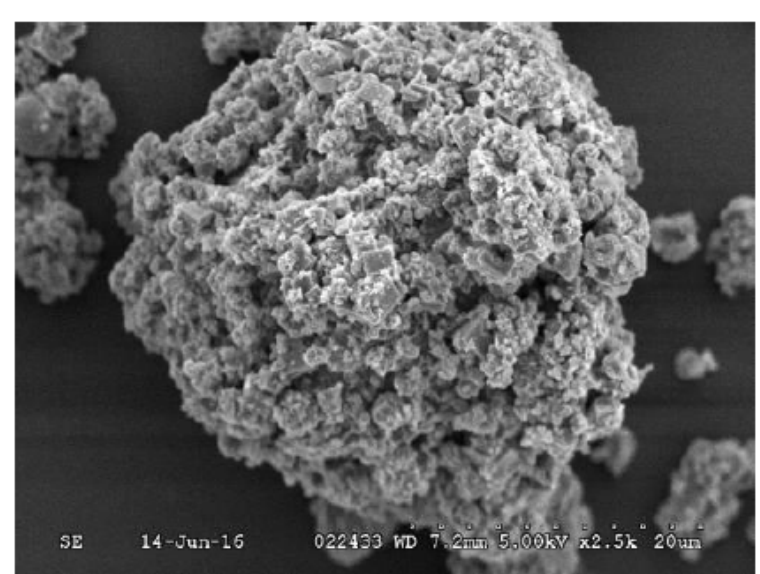

(a)

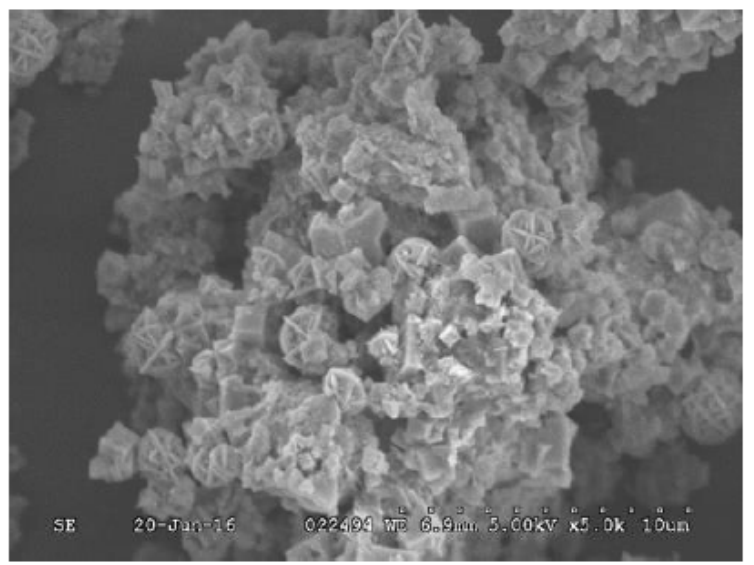

(b)

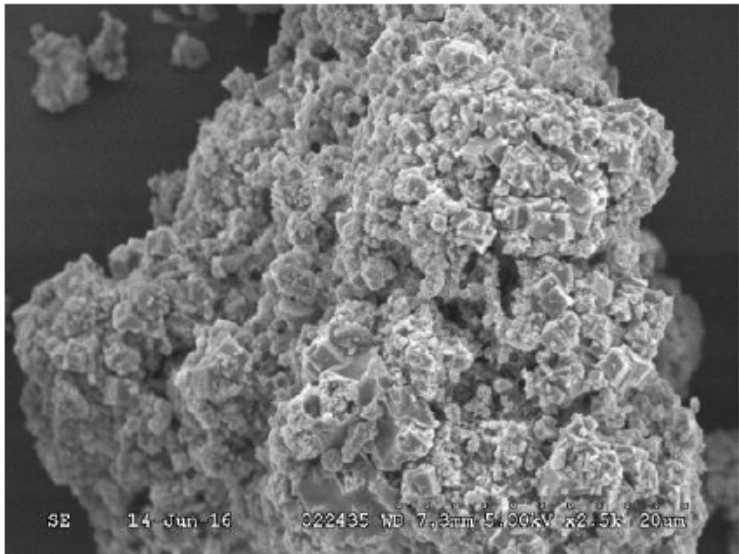

(b)

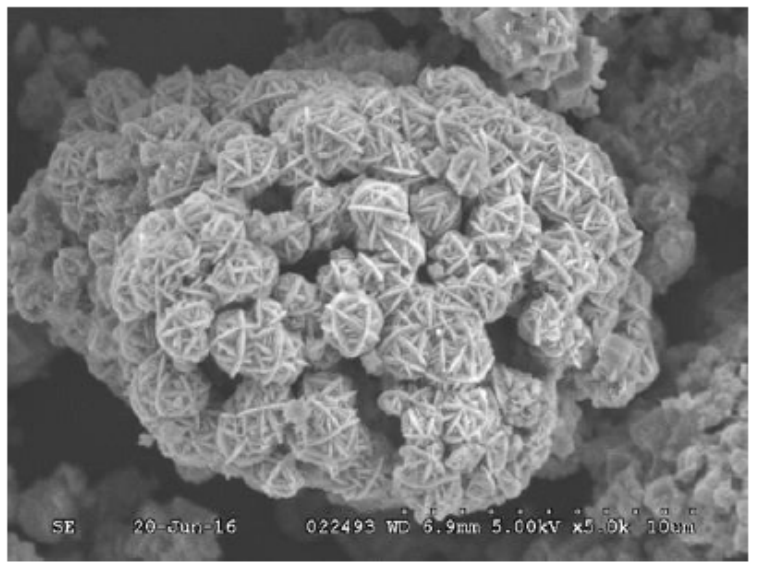

(c)

Fig. 8. SEM images of zeolitized CFA with (a) Deionized Water (b) first recycled stream (c) Second recycled stream (d) Third recycled stream

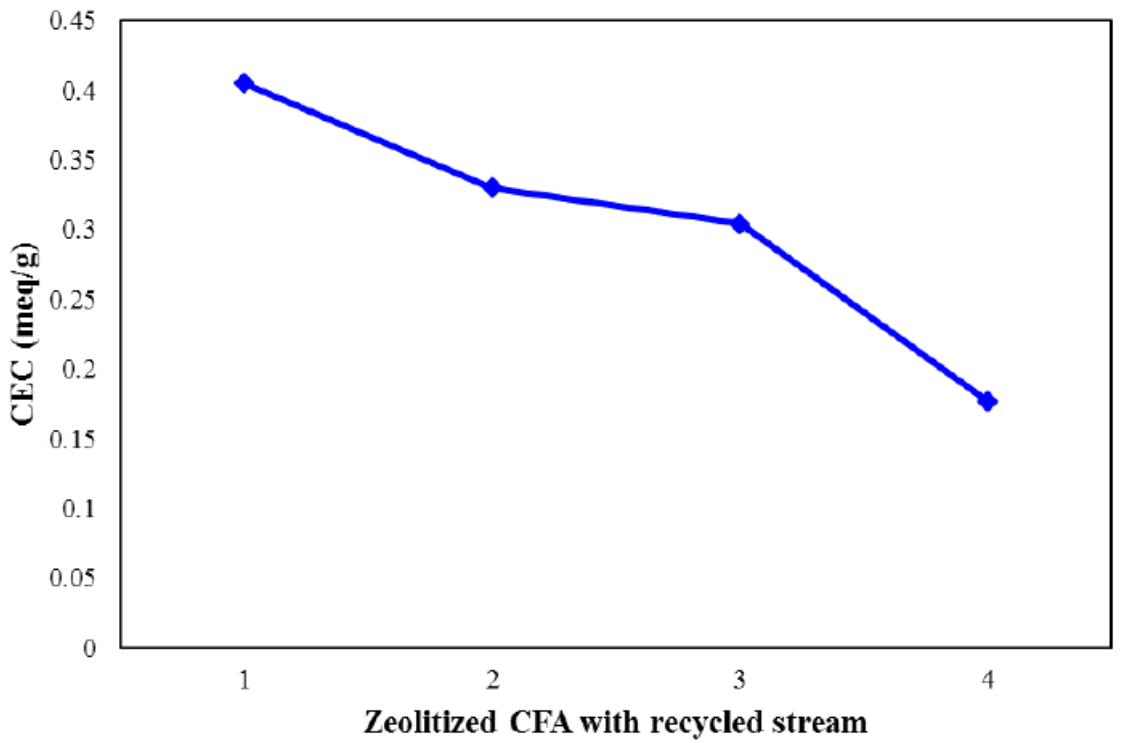

Fig. 9. CEC of zeolitized CFA with Deionized water, first recycled stream, second recycled stream, third recycled stream 


\section{Cation Exchange Capacity (CEC)}

The Cation Exchange Capacity (CEC) is an important physical property of the zeolitic materials and is related to the quality of a zeolite species. Figure 9 illustrates the CEC of the zeolitized CFA synthesized with various reaction solvents.

The zeolitized CFA synthesized with DI water had the highest CEC with $0.405 \mathrm{meq} / \mathrm{g}$ and as the consecutive recycled stream was used, the resulting product had lower CEC, $0.330,0.305$ and $0.177 \mathrm{meq} / \mathrm{g}$, respectively. A lower CEC has been previously observed when utilizing waste stream instead of pure water (Behin et al., 2014; Bukhari et al., 2014). The decrease in the CEC of the synthesized samples can be attributed to the higher production of hydroxysodalite. Since, hydroxysodalite has lower CEC values than zeolite A (Derkowski et al., 2007).

\section{Conclusion}

Two sets of experiments converting CFA to zeolite were conducted utilizing the continuous flow MW reactor. The first set of experiment was conducted to investigate the effects of MW power on the zeolitization. It was observed that higher power of MW irradiation resulted in a faster crystal growth while after $150 \mathrm{~min}$ of reaction it was observed that the crystallinity reached a maximum regardless of MW power.

The first set of experiment indicates that MW power is directly correlated to the zeolite crystal growth. Higher MW irradiation power results in faster crystal growth, however, the MW irradiation does not affect the nucleation rate neither does it increase the overall conversion. This result can be used to optimize the MW power irradiation and reaction time for the zeolitization process of CFA in larger scales.

The second set of experiment was conducted with recycled waste liquid stream. The ICP analysis was conducted after digestion and after crystallization for each run. The concentration of silicon and aluminum significantly increased after each digestion step and decreased after crystallization. This signifies the dissolution of aluminosilicate constituents of CFA. The subsequent decrease of silicon and aluminum concentration in the slurry was due to the crystallizing of zeolitic crystals on the surface of CFA particles. However, each consecutive recycled stream showed lower amount of aluminosilicate. This indicates that the waste stream produced by the zeolitization process cannot be recycled indefinitely. This is also observed through XRD and SEM analysis. The XRD analysis indicated that the crystallinity of the zeolite produced with successive recycled streams was lower while the SEM showed a higher production of hydroxysodalite compared to zeolite-A. The CEC analysis further indicated that the zeolite produced with DI water had higher CEC of $0.405 \mathrm{meq} / \mathrm{g}$ compared to the runs with the recycled streams of $0.330,0.305$ and $0.177 \mathrm{meq} / \mathrm{g}$. The decreased in the CEC for each recycled stream can be attributed to the higher production of hydroxysodalite. Moreover, higher concentration of metallic ions can hamper the production of zeolite-A, therefore, consecutive recycling of the waste stream can reduce the CEC of the product.

\section{Acknowledgment}

The authors gratefully acknowledge the Natural Sciences and Engineering Council of Canada (NSERC) and Newalta.

\section{Author's Contributions}

The experiments were conducted by Dr. Salman Bukhari as part of his $\mathrm{PhD}$ research project, under the supervision of Prof. Sohrab Rohani. The draft of the manuscript was prepared by Salman Bukhari and revised by Sohrab Rohani.

\section{Ethics}

The material presesnted inthis manuscript are the work of the aothors.

\section{References}

Aldahri, T., J. Behin, H. Kazemian and S. Rohani, 2016. Synthesis of zeolite Na-P from coal fly ash by thermo-sonochemical treatment. Fuel, 182: 494-501. DOI: 10.1016/j.fuel.2016.06.019

Babajide, O., N. Musyoka, L. Petrik and F. Ameer, 2012. Novel zeolite Na-X synthesized from fly ash as a heterogeneous catalyst in biodiesel production. Catal. Today, 190: 54-60.

DOI: $10.1016 / j$.cattod.2012.04.044

Baerlocher, C., L.B. McCusker and D.H. Olson, 2007. Atlas of Zeolite Framework Types. 6th Edn., Elsevier, New York, ISBN-10: 0080554342, pp: 404.

Bain, D.C. and B.F.L. Smith, 1987. Chemical Analysis. In: Determinative Methods Clay Mater, Blackie, Chapman and Hall, Glasgow, New York, pp: 248-274.

Behin, J., S.S. Bukhari, H. Kazemian and S. Rohani, 2016. Developing a zero liquid discharge process for zeolitization of coal fly ash to synthetic NaP zeolite. Fuel, 171: 195-202.

DOI: 10.1016/j.fuel.2015.12.073

Behin, J., S.S. Bukhari, V. Dehnavi, H. Kazemian and S. Rohani, 2014. Using Coal Fly Ash and wastewater for microwave synthesis of LTA zeolite. Chem. Eng. Technol., 37: 1532-1540.

DOI: $10.1002 /$ ceat.201400225 
Belviso, C., F. Cavalcante, A. Lettino and S. Fiore, 2009. Zeolite synthesised from fused coal fly ash at low temperature using seawater for crystallization. Coal Combust. Gasif. Prod., 1: 7-13.

DOI: $10.4177 /$ ccgp-d-09-00004.1

Belviso, C., F. Cavalcante, A. Lettino and S. Fiore, 2011. Effects of ultrasonic treatment on zeolite synthesized from coal fly ash. Ultrason. Sonochem., 18: 661-668. DOI: 10.1016/j.ultsonch.2010.08.011

Breck, D.W., 1975. Zeolite molecular sieves: Structure, chemistry and use. Anal. Chim. Acta, 75: 493-493. DOI: $10.1016 / \mathrm{S} 0003-2670(01) 85391-5$

Bukhari, S.S., J. Behin, H. Kazemian and S. Rohani, 2014. A comparative study using direct hydrothermal and indirect fusion methods to produce zeolites from coal fly ash utilizing single-mode microwave energy. J. Mater. Sci., 49: 8261-8271.

DOI: $10.1007 / \mathrm{s} 10853-014-8535-2$

Bukhari, S.S., J. Behin, H. Kazemian and S. Rohani, 2015a. Conversion of coal fly ash to zeolite utilizing microwave and ultrasound energies: A review. Fuel, 140: 250-66. DOI: 10.1016/j.fuel.2014.09.077

Bukhari, S.S., J. Behin, H. Kazemian and S. Rohani, $2015 \mathrm{~b}$. Synthesis of zeolite NA-A using single mode microwave irradiation at atmospheric pressure: The effect of microwave power. Can. J. Chem. Eng., 93: 1081-1090. DOI: $10.1002 /$ cjce. 22194

Bukhari, S.S., S. Rohani and H. Kazemian, 2016. Effect of ultrasound energy on the zeolitization of chemical extracts from fused coal fly ash. Ultrason. Sonochem., 28: 47-53. DOI: 10.1016/j.ultsonch.2015.06.031

Cheung, O. and N. Hedin, 2014. Zeolites and related sorbents with narrow pores for $\mathrm{CO}_{2}$ separation from flue gas. RSC Adv., 4: 14480-14494. DOI: $10.1039 / \mathrm{C} 3 \mathrm{RA} 48052 \mathrm{~F}$

Dehnavi, V., B.L. Luan, D.W. Shoesmith, X.Y. Liu and S. Rohani, 2013. Effect of duty cycle and applied current frequency on Plasma Electrolytic Oxidation (PEO) coating growth behavior. Surf. Coat. Technol., 226: 100-107.

DOI: 10.1016/j.surfcoat.2013.03.041

Derkowski, A., W. Franus, H. Waniak-Nowicka and A. Czimerova, 2007. Textural properties Vs. CEC and EGME retention of $\mathrm{Na}-\mathrm{X}$ zeolite prepared from fly ash at room temperature. Int. J. Miner. Process., 82: 57-68. DOI: 10.1016/j.minpro.2006.10.001

Fan, Y., F.S. Zhang, J. Zhu and Z. Liu, 2008. Effective utilization of waste ash from MSW and coal cocombustion power plant-Zeolite synthesis. J. Hazard. Mater., 153: 382-388.

DOI: $10.1016 /$ j.jhazmat.2007.08.061

Heidrich, C., H. Feuerborn and A. Weir, 2013. Coal combustion products: A global perspective. World Coal Ash WOCA, Lexington, KY.
Holler, H. and U. Wirsching, 1985. Zeolite formation from fly ash. Fortschr Mineral., 63: 21-43.

Hollman, G.G., G. Steenbruggen and M. JanssenJurkovičová, 1999. A two-step process for the synthesis of zeolites from coal fly ash. Fuel, 78: 1225-1230. DOI: 10.1016/S0016-2361(99)00030-7

Hussar, K., S. Teekasap and N. Somsuk, 2017. Synthesis of Zeolite a form by-product of aluminum etching process: Effects of reaction temperature and reaction time on pore volume. Am. J. Environ. Sci., 7: 35-42. DOI: 10.3844/ajessp.2011.35.42

IEA, 2013. World energy outlook 2013. International Energy Agency, Paris.

Khan, A.Z., S. Nigar, S.K. Khalil, S. Wahab and A. Rab et al., 2013. Influence of synthetic zeolite application on seed development profile of soybean grown on allophanic soil. Pak. J. Bot., 45: 1063-1068.

Khodabandeh, S., 1997. Synthesis of alkaline-earth zeolites. California Institute of Technology.

Landau, M.V., L. Vradman, V. Valtchev, J. Lezervant and E. Liubich et al., 2003. Hydrocracking of heavy vacuum gas oil with a $\mathrm{Pt} / \mathrm{H}$-beta- $\mathrm{Al}_{2} \mathrm{O}_{3}$ catalyst: Effect of zeolite crystal size in the nanoscale range. Ind. Eng. Chem. Res., 42: 2773-2782. DOI: $10.1021 / \mathrm{ie} 020899$ o

Malekpour, A., M.R. Millani and M. Kheirkhah, 2008. Synthesis and characterization of a $\mathrm{NaA}$ zeolite membrane and its applications for desalination of radioactive solutions. Desalination, 225: 199-208. DOI: 10.1016/j.desal.2007.02.096

Moreno, N., X. Querol, C. Ayora, A. Alastuey and C. Fernández-Pereira et al., 2001. Potential environmental applications of pure zeolitic material synthesized from fly ash. J. Environ. Eng., 127: 994-1002.

DOI: 10.1061/(ASCE)0733-9372(2001)127:11(994)

Moriyama, R., S. Takeda, M. Onozaki, Y. Katayama and K. Shiota et al., 2005. Large-scale synthesis of artificial zeolite from coal fly ash with a small charge of alkaline solution. Fuel, 84: 1455-1461. DOI: $10.1016 /$ j.fuel.2005.02.026

Musyoka, N.M., L.F. Petrik and E. Hums, 2011. Ultrasonic assisted synthesis of zeolite A from coal fly ash using mine waters (acid mine drainage and circumneutral mine water) as a substitute for ultra pure water. International Mine Water Association, (MAW' 11), Aachen, Germany, pp: 423-428.

Musyoka, N.M., L.F. Petrik, G. Balfour, W.M. Gitari and E. Hums, 2011. Synthesis of hydroxy sodalite from coal fly ash using waste industrial brine solution. J. Environ. Sci. Health A, 46: 1699-1707. DOI: 10.1080/10934529.2011.623961

Musyoka, N.M., L.F. Petrik, O.O. Fatoba and E. Hums, 2013. Synthesis of zeolites from coal fly ash using mine waters. Miner. Eng., 53: 9-15. DOI: 10.1016/j.mineng.2013.06.019 
Querol, X., A. Alastuey, A. López-Soler, F. Plana and J.M. Andrés et al., 1997. A fast method for recycling fly ash: Microwave-assisted zeolite synthesis. Environ. Sci. Technol., 31: 2527-2533. DOI: $10.1021 / \mathrm{es} 960937 \mathrm{t}$

Querol, X., J.C. Umaña, F. Plana, A. Alastuey and A. Lopez-Soler et al., 2001. Synthesis of zeolites from fly ash at pilot plant scale. Examples of potential applications. Fuel, 80: 857-865.

DOI: 10.1016/S0016-2361(00)00156-3

Savage, N. and M.S. Diallo, 2005. Nanomaterials and water purification: Opportunities and challenges. J. Nanoparticle Res., 7: 331-342.

DOI: $10.1007 / \mathrm{s} 11051-005-7523-5$

Shigemoto, N., H. Hayashi and K. Miyaura, 1993. Selective formation of $\mathrm{Na}-\mathrm{X}$ zeolite from coal fly ash by fusion with sodium hydroxide prior to hydrothermal reaction. J. Mater. Sci., 28: 4781-4786. DOI: 10.1007/BF00414272

Shoumkova, A., 2011. Zeolites for water and wastewater treatment: An overview. Australian Institute of High Energy Materials.

Sinha, P.K., P.K. Panicker, R.V. Amalraj and V. Krishnasamy, 1995. Treatment of radioactive liquid waste containing caesium by indigenously available synthetic zeolites: A comparative study. Waste Manage., 15: 149-157.

DOI: $10.1016 / 0956-053 X(95) 00014-Q$
Srinivasan, A. and M.W. Grutzeck, 1999. The adsorption of $\mathrm{SO}_{2}$ by zeolites synthesized from fly ash. Environ. Sci. Technol., 33: 1464-9146.

DOI: $10.1021 / \mathrm{es} 9802091$

Theron, J., J.A. Walker and T.E. Cloete, 2010. Nanotechnology and water treatment: Applications and emerging. Nanotechnol. Water Treat. Applied.

Treacy, M.M.J. and J.B. Higgins, 2007. Collection of simulated XRD powder patterns for zeolites. Elsevier, Amsterdam, The Netherlands.

Wang, S. and Y. Peng, 2010. Natural zeolites as effective adsorbents in water and wastewater treatment. Chem. Eng. J., 156: 11-24. DOI: $10.1016 /$ j.cej.2009.10.029

Wang, S. and Z.H. Zhu, 2005. Sonochemical treatment of fly ash for dye removal from wastewater. J. Hazard. Mater., 126: 91-95. DOI: 10.1016/j.jhazmat.2005.06.009

Wdowin, M., M.M. Wiatros-Motyka, R. Panek, L.A. Stevens and W. Franus et al., 2014. Experimental study of mercury removal from exhaust gases. Fuel, 128: 451-457. DOI: $10.1016 /$ j.fuel.2014.03.041 